\title{
Hanan y Hurin: historia de un sistema estructural inca
}

Hanan et Hurin : histoire d'un système structurel inca

Hanan and Hurin: history of an inca structural system

Isabel Yaya

\section{(2) OpenEdition}

\section{Journals}

Edición electrónica

URL: http://journals.openedition.org/bifea/4049

DOI: $10.4000 /$ bifea. 4049

ISSN: 2076-5827

Editor

Institut Français d'Études Andines

Edición impresa

Fecha de publicación: 1 agosto 2013

Paginación: 173-202

ISSN: 0303-7495

\section{Referencia electrónica}

Isabel Yaya, " Hanan y Hurin: historia de un sistema estructural inca », Bulletin de I'Institut français d'études andines [En línea], 42 (2) | 2013, Publicado el 08 agosto 2013, consultado el 05 noviembre 2020. URL : http://journals.openedition.org/bifea/4049; DOI : https://doi.org/10.4000/bifea.4049

\section{(@) $\Theta \Theta \Theta$}

Les contenus du Bulletin de l'Institut français d'études andines sont mis à disposition selon les termes de la licence Creative Commons Attribution - Pas d'Utilisation Commerciale - Pas de Modification 4.0 International. 


\title{
Hanan y Hurin: historia de un sistema estructural inca*
}

Isabel Yaya**

\begin{abstract}
Resumen
Los relatos dinásticos incas transcritos después de la conquista española describen de manera contradictoria la partición social y espacial del Cuzco antiguo en mitades asimétricas (hanan/hurin). Dichos relatos no concuerdan sobre la identidad del soberano a la iniciativa de esta división, ni sobre los principios de clasificación que la fundan. La mayoría de los historiógrafos modernos atribuyen estas discrepancias narrativas a los actores coloniales. Estos habrían modificado la historia inca, ya sea por incomprensión cultural y lingüística o por estrategia, a fin de asentar jurídicamente el sistema colonial $y$, con este, sus pretensiones personales. Este artículo propone una lectura alternativa y considera estas discordancias no solo como el resultado de contaminaciones coloniales, sino también como el indicio de un discurso inca ambivalente sobre la perpetuidad dinástica.
\end{abstract}

Palabras clave: Incas, historiografía, relatos dinásticos, dualidad, panacas

\section{Hanan et Hurin : histoire d'un système structurel inca}

\section{Résumé}

Les récits dynastiques incas transcrits après la conquête espagnole décrivent de manière contradictoire la partition sociale et spatiale de Cuzco en moitiés asymétriques (hanan/hurin). Ils ne s'accordent ni sur l'identité du souverain à l'initiative de cette division, ni sur les principes de classification qui la fondent. Longtemps, ces divergences narratives ont été imputées aux acteurs coloniaux. Ceux-ci auraient remanié l'histoire inca soit par mécompréhension culturelle/linguistique, soit par stratégie,

* Este artículo está basado en una ponencia presentada en el Séminaire d'Anthropologie Américaniste (EHESS), París, Francia, en marzo de 2011.

** Leverhulme Visiting Fellow, School of Advanced Study (University of London). E-mail: isabel.yaya@ sas.ac.uk 
afin d'asseoir juridiquement le système colonial et, avec lui, leurs prétentions personnelles. À l'inverse, cet article propose d'envisager ces discordances non pas uniquement comme le fait de contaminations coloniales, mais également comme l'indice d'un discours inca ambivalent sur la perpétuation de la dynastie.

Mots clés : Incas, historiographie, récits dynastiques, dualisme, panacas

\title{
Hanan and Hurin: history of an inca structural system
}

\begin{abstract}
The inca dynastic narratives recorded after the Spanish conquest describe in discrepant ways the social and spatial partition of Cuzco into asymmetric moieties (hanan/hurin). They neither agree on the identity of the ruler who initiated this division, nor on the classification principles that founded it. Over the years, these narrative discrepancies were thought to be imprints of colonial actors who would have altered Inca history through cultural/linguistic miscomprehension or strategy. They intended in this way to legally establish the colonial system and, with it, their personal pretensions. As an alternative perspective, this article proposes to consider these contradictions not only as a result of colonial contaminations, but also as being an indication of an ambivalent Inca discourse on dynastic perpetuation.
\end{abstract}

Keywords: Incas, historiography, dynastic narratives, dualism, panacas

\section{INTRODUCCIÓN}

Las fuentes coloniales nos dicen que la dinastía real inca se dividía en dos bandos llamados Hurin y Hanan, los cuales se sucedieron a la cabeza del Tawantinsuyu en el transcurso del tiempo. Los cinco primeros gobernantes pertenecieron a la división Hurin que espacialmente correspondía a la parte baja del Cuzco, donde vivieron los linajes procedentes de estos soberanos. Según los mismos textos, los siete a nueve últimos reyes tuvieron su origen en la división Hanan que coincidía espacialmente con la parte alta de la ciudad, donde residieron sus descendientes. $\mathrm{Si}$ los cronistas concuerdan sobre este marco general de organización, divergen sin embargo sobre el período y los motivos de la creación de estas mitades y particularmente sobre el modo de afiliación a cada división, el cual dependía directamente de la constitución de los linajes reales. Así, mientras algunas fuentes afirman que los dos bandos fueron creados uno a continuación del otro, de la misma manera que los grupos de parentesco real fueron instituidos sucesivamente a la muerte de cada soberano, otras alegan que todas estas familias nobles ya existían cuando un rey reformista las dividió en dos parcialidades de estatus asimétrico. El primer conjunto de textos redactados por Pedro Sarmiento de Gamboa (1572), Miguel Cabello de Balboa (1586) y Martín de Murúa (15901602), insiste sobre el carácter linear de la genealogía real, mientras los autores 
del segundo grupo, incluidos Juan de Betanzos (1551), Bartolomé de Las Casas (1562-1564), Jerónimo Román y Zamora (1575) y Pedro Gutiérrez de Santa Clara (c. 1590), utilizan el vocabulario del parentesco para explicar la posición de cada miembro de la nobleza en la estructura dualista del grupo de descendencia inca.

Desde los primeros estudios sistemáticos de las fuentes coloniales en la segunda mitad del siglo XIX, los investigadores han gastado mucha tinta discutiendo sus contradicciones. Entre ellos, Eduard G. Seler, más conocido por sus distinguidos trabajos sobre las culturas mesoamericanas, fue el primero en proponer una lectura sociológica de la división dualista de la genealogía inca. Seler planteó la existencia de una monarquía doble dirigida por las parcialidades Hanan y Hurin, ambas pertenecientes a una única familia noble denominada Khapak Ayllu (Seler, 1915 [1894]). Setenta años después, Tom R. Zuidema (1962) se inspiró en estas contribuciones para sugerir que el sistema de mitades equivale a una diarquía asimétrica implícita cuyas divisiones integraban clases de matrimonio. Según su lectura, el registro genealógico inca no proporcionaba un informe de eventos factuales sino que perpetuaba un conjunto de mitos acerca de los antepasados fundadores de los linajes reales, y ofrecía así un modelo del orden político. Pierre Duviols (1979b), a pesar de su desacuerdo con Zuidema sobre su interpretación exclusivamente mitológica de la tradición oral inca, se adhirió a la hipótesis de una diarquía inca. Según el historiador francés, los cronistas malinterpretaron los testimonios de sus informantes indígenas de tal modo que amoldaron a un relato linear lo que originalmente fue una regencia compartida entre los linajes Hanan y Hurin. El Sapa Inca (único Inca) habría sido originario de la parte alta, mientras el título de su «segunda persona» habría sido concedido al principal de la parte baja. Para resolver el desequilibrio en el número de soberanos tradicionalmente documentados en cada mitad, Duviols sugiere que la serie Hanan de nueve generaciones refleja fielmente la duración dinástica de la que se omitieron algunos reyes pertenecientes a Hurin. Su enfoque considera así que las fuentes coloniales proporcionan marcadores temporales para estimar la duración de los reinados incas. Como Peter Gose (1996) lo ha demostrado de manera concluyente, las evidencias primarias a favor de la organización diárquica de la función gubernativa más alta del imperio son extremadamente escasas y problemáticas. Aunque existían precedentes generalizados de estructuras sociopolíticas dualistas a nivel provincial en los Andes, las fuentes coloniales concuerdan en describir un ejercicio de poder unilateral en la cumbre de la jerarquía inca (Pärssinen, 1992: 200 y ss.). Ya sea que el rey delegaba la aplicación de algunas decisiones a un segundo al mando, o que encomendaba la conducta de su ejército a un pariente apto, no descarta el carácter autocrático del sistema reinante. Asimismo, el rey podía pedir consejos ante un asesor de alto rango o nombrar un gobernador en Cuzco cuando estaba en guerra sin que su supremacía fuera cuestionada. La mayoría de las monarquías imponen instrumentos de gobierno similares que no controvierten la absoluta autoridad del

1 El ayllu es la estructura elemental andina de organización social que designa una unidad de tipo corporativo cuyos miembros se reclaman de un antepasado común. 
rey. El hecho de que los intereses locales de cada mitad estuvieran encargados a su jefe respectivo no implicaba necesariamente una diarquía institucionalizada a nivel del Estado en la cual el poder sería efectivamente dividido en distintos dominios. Lejos de esta visión, las crónicas describen a un rey quien acumulaba una suprema autoridad sobre todas las esferas sociopolíticas, incluso la ritual y militar, aunque otros miembros de la élite disfrutaban de oficios importantes en diferentes esferas, como el Señor que los españoles identificaron con el sacerdote mayor del Sol. Sin embargo, ninguno de ellos poseía un poder exclusivo o independiente, de manera que el Sapa Inca ejercía el mando absoluto del Tawantinsuyu. Como ya lo observó John Rowe, el sistema político inca estuvo basado en el principio monárquico (1946: 257). El ritual de investidura real corrobora esta lectura ya que estaba centrado en la elección divina de un solo individuo considerado como el hijo del antepasado divino de la dinastía inca, el Sol, padre de Manco Capac. Por último, el modelo diárquico no explica por qué los relatos sobre las dinastías incas presentan tantas variaciones y contradicciones sobre el fundamento de la división espacial y social bipartita del Cuzco, la identidad de su instigador y, lo que es más importante aún, sobre los principios de afiliación que gobernaban las mitades Hanan y Hurin. Indiscutiblemente, la incomprensión cultural y las estrategias de legitimación colonial no explican esta variabilidad en su totalidad.

Este trabajo propone una nueva interpretación de la organización dualista del Cuzco antiguo. En primer lugar, invita a una reflexión sobre el tratamiento de las incongruencias del registro inca del pasado por la historiografía moderna ya que este enfoque se aplicó precisamente a la lectura de las divergencias sobre el origen de las mitades cuzqueñas. Este examen crítico evidencia los escollos que nacen de considerar las discrepancias de las fuentes primarias como anomalías del registro histórico original. Devuelve así a la tradición oral inca su dimensión política y, por definición, controvertible, cuyas divergencias narrativas fueron estructurales en cierta forma. La segunda parte de este trabajo aplica estas consideraciones al estudio de los relatos sobre el origen de la división dualista cuzqueña. El análisis comparativo de los aspectos discursivos y de los datos sociológicos contenidos en cada relato muestra que la primogenitura fue la regla ideal de sucesión real y un principio fundamental de organización segmentaria que aclara el sistema de oposición entre Hanan y Hurin.

\section{LAS INCONGRUENCIAS DE LA HISTORIA INCA Y LA HISTORIOGRAFÍA}

Desde la aparición de un interés europeo por el pasado del Perú antiguo, los historiadores se han esforzado por esclarecer las contradicciones e incoherencias que Ilenan las transcripciones coloniales de los relatos dinásticos incas. Una lectura comparativa de las fuentes primarias revela, por ejemplo, que son muchas las que no concuerdan en cuanto al número y la identidad de los soberanos cuzqueños anteriores a la venida de los conquistadores (Covey, 2006; Ramírez, 2006). Tampoco están de acuerdo sobre la atribución a tal o cual rey de nuevas 
conquistas, instauración de festividades y reformas políticas. Además, estos datos contradictorios no se limitan a textos redactados por diferentes autores, sino que se pueden notar en un mismo documento. Lo atestigua la descripción de las reglas de sucesión, que según varios cronistas seguía el principio de primogenitura masculina. Esta prescripción estipulaba que el legítimo heredero del título real sería el hijo mayor del rey con su esposa principal (Betanzos, 1987 [1551], Lib. I, cap. XVI: 75, 78; Discurso, 1920 [1543-1608]: 12; Sarmiento, 1988 [1572], cap. XIV: 63; Fernández, 1963 [1571], T. 2, Lib. III, cap. V: 80; Garcilaso de la Vega, 1985 [1609], Lib. IV, cap. IX: 186-187). Los mismos autores, habiendo asentado esta regla, relatan muchas ocurrencias de sucesión real en las que se opta por el candidato más apto a gobernar indistintamente a sus lazos de parentesco con su predecesor.

Varios cronistas de los siglos XVI y XVII notan estas incongruencias, las cuales aprovecharon para desacreditar la veracidad histórica de las obras de sus predecesores y plantear así su propia interpretación. Entre ellos, Garcilaso de la Vega consideraba algunas de estas divergencias narrativas como errores de parte de los autores españoles quienes no dominaban el idioma de los incas. El historiador mestizo se proponía restablecer la verdadera y única descripción de los hechos de sus antepasados peruanos:

Solo serviré de comento para declarar y ampliar muchas cosas que [los españoles] asomaron a decir y las dejaron imperfectas por haberles faltado relación entera. Otras muchas cosas se añadirán que faltan de sus historias y pasaron en hecho de verdad, y algunas se quitaran que sobran, por falsa relación que tuvieron, por no saberla pedir en español con distinción de tiempos y edades y división de provincias y naciones, o por no entender al indio que se la daba o por no entenderse el uno al otro, por la dificultad del lenguaje (Garcilaso de la Vega, 1985 [1609], Lib. I, cap. XIX: 46).

Otros cronistas, como Bernabé Cobo, imputaron las variaciones narrativas sobre un mismo tema al juicio desordenado de los naturales. El Padre jesuita, sin embargo, compartía con Garcilaso el objetivo de presentar a sus lectores una reconstitución auténtica y, en consecuencia, única de la antigüedad del Perú:

De muchas maneras cuentan los indios peruanos el origen y principio de los Incas sus reyes, envolviendo tan gran confusión y variedad de desatinos, que por su relación no es posible averiguar cosa cierta (Cobo, 1964 [1653], Lib. XII, cap. III: 61).

Cobo sigue su descripción, resumiendo una serie de relatos sobre el origen de los Incas, antes de concluir:

$\mathrm{Y}$ a este tono refieren un mundo de disparates y los apoyan con tan flacas razones, como lo son las mismas opiniones (Cobo, 1964 [1653], Lib. XII, cap. III: 61).

Asimismo, la mayoría de los estudios modernos atribuyen las divergencias narrativas de las crónicas a dos factores principales. Uno es endógeno a la tradición oral inca y se refiere a su presunto carácter mitológico, mientras que el 
otro es exógeno a ella y recae sobre la responsabilidad de los actores coloniales. La primera perspectiva considera que los relatos dinásticos de la élite cuzqueña fueron elaboraciones mitológicas que no tuvieron por objeto transmitir un pasado factual, ni siquiera convocar lo sobrenatural o lo divino para interpretar eventos concretos, sino más bien que buscaron ofrecer una exégesis de las instituciones incas. Con este fin, emplean un lenguaje mítico cuya estructura es típicamente multivocal y aberrante pero que utiliza la metáfora para dar cuenta de un modelo social. El antropólogo Tom R. Zuidema dice:

La 'historia' inca integraba hechos religiosos, calendáricos, rituales y memorables en un sistema ideológico, el cual era jerárquico en términos de espacio y tiempo. Esta ideología jerárquica inca no debe ser confundida con la concepción linear occidental de la historia impuesta por los españoles (Zuidema, 1982: 173-174).

Según esta lectura, los marcadores temporales de las narraciones incas, como las nuevas conquistas, las genealogías reales, o la construcción de nuevos edificios, forman una estructura mítica y política extraña al desarrollo objetivo de los hechos. De esta manera, el carácter mitológico de los relatos y su transcripción de acuerdo a los formatos narrativos occidentales explicarían las incoherencias presentes en las fuentes primarias. Una segunda explicación de la multiplicidad de datos divergentes en dichas fuentes es la situación colonial. Sobre este tema, numerosos estudios han proporcionado evidencias irrefutables según las cuales parte de las incoherencias de las fuentes se originaron en la obtención de privilegios individuales, la explotación de recursos andinos por parte de la Corona española, o la evangelización de los nativos (Duviols, 1971; 1979a; MacCormack, 1991; Villarías Robles, 1998). Además, no cabe duda de que la incomprensión lingüística y cultural también afectó la transcripción de los relatos incas, como lo sugirió Garcilaso hace cuatro siglos. Sin embargo, aunque la historiografía moderna ha dado un nuevo enfoque a las crónicas para posicionarlas adecuadamente en el marco de la historia intelectual y política colonial, no ha logrado explicar todas las discrepancias narrativas que éstas presentan. Los relatos del origen de la división bipartita del Cuzco ilustran precisamente esta encrucijada. Divergen sobre varios aspectos, incluyendo la época en que ocurre la división, su instigador y sus consecuencias sobre el sistema de prestigio jerárquico. Estos elementos varían, no solamente de un autor a otro, sino que los cronistas evocan también la coexistencia de diferentes narraciones sobre este evento (Sarmiento, 1988 [1572], cap. XIX: 72; Cobo, 1964 [1653], Lib. XII, cap. III-IV, IX; 63-66, 72). Para resolver estas contradicciones, cada cronista eligió la versión que juzgaba más verosímil, confiándose en parte en la autoridad de sus informantes indígenas y en el realismo de la descripción, acomodándola a las convenciones narrativas europeas.

En tal contexto, ¿cómo identificar los criterios objetivos que nos permitan reconocer el informe auténtico entre varios relatos conflictivos? Si existen tales índices, ¿cómo determinar que estos son de origen prehispánico y no fueron introducidos por el cronista para dar una consistencia histórica a su discurso? ¿Podemos realmente juzgar la objetividad histórica de las narraciones incas cuando 
no poseemos vestigios materiales para elaborar una comparación independiente? Las investigaciones arqueológicas apenas empiezan a proporcionarnos datos cronológicos confiables, los cuales indican además que la expansión inca habría empezado desde el siglo XIV, más de 100 años antes de la fecha sugerida en la documentación (Covey, 2006).

Pero, si la verosimilitud de las narraciones no es un criterio confiable para determinar su autenticidad, las divergencias narrativas tampoco pueden ser atribuidas únicamente a los actores coloniales porque, ya antes de la conquista española, los relatos dinásticos incas fueron elaboraciones históricas que no formaban un corpus inalterable y coherente. Sobre este punto, María Rostworowski (1988: 12-14) observó que los cronistas fallaron en comprender plenamente no solo un sistema sociopolítico ajeno a su propio sistema, sino también registros de memoria radicalmente distintos. De hecho, las fuentes primarias indican que los incas concibieron al menos dos medios diferentes de conservación de la memoria: las famosas cuerdecillas anudadas llamadas khipus y unos tablones pintados (Acosta, 1962 [1590], Lib. VI, cap. VIII: 290). Los primeros registraban un conjunto variado de datos administrativos y también los relatos épicos relativos a la vida de los reyes difuntos. Estaban en posesión de especialistas (khipukamayuq) únicos capaces de enunciar su contenido. Los segundos, nos dice el Padre Cristóbal de Molina (1989 [1575]: 50), describían «la vida de cada uno de los yngas y de las tierras que conquistó, pintado por sus figuras». Estaban conservados en el Puqin kancha, una casa del Sol ubicada a «tres tiros de arcabuz de la ciudad» (Cobo, 1964 [1653], Lib. XIII, cap. XVI: 185). Este mismo autor afirma que el relato del origen de los Incas en su crónica proviene de estos tablones, aunque sin especificar cómo tuvo acceso a estas informaciones. Cobo (1964 [1653], Lib. XII, cap. II: 59) asegura que Polo de Ondegardo también usó representaciones similares para documentar su propia crónica2. Sarmiento sitúa la confección de estas obras bajo el reinado de Pachacuti Yupanqui después de que el soberano convocó a todos los historiadores de su dominio para que le relataran sus tradiciones ancestrales:

Y después que tuvo bien averiguado todo lo más notable de las antigüedades de sus historias, hízolo todo pintar por su orden en tablones grandes, y deputó en las Casas del Sol una gran sala, adonde las tales tablas, que guarnecidas de oro estaban, estuviesen como nuestras librerías, y constituyó doctores que supiesen entenderlas y declararlas. Y no podían entrar, donde estas tablas estaban, sino el inca o los historiadores, sin expresa licencia del inca (Sarmiento de Gamboa, 1988 [1572], cap. IX: 49).

Así, la historia de la dinastía inca estaba registrada en dos medios de comunicación con modalidades de uso distintas. Además de la variabilidad implícita de estos

2 Cobo asegura que vio una de las pinturas en tapicería de cumbi (tejido fino) que Polo de Ondegardo aprovechó para documentar sus escritos sobre la historia de los Incas. En su estudio «Quipu y Quilca», Raúl Porras Barrenechea (1999 [1947]) cita dos documentos que mencionan la existencia de tablones sobre los cuales estaba escrita la edad de los reyes a su muerte, mientras que otros registraban informaciones relativas a la legislación del imperio. A propósito de estas tablas y su lazo eventual con el sistema de tuqapu, véase en particular Cummins (2002: 128-139). 
recursos, los relatos guardados en khipus estaban en custodia de varios grupos de parentesco que mantenían su agenda propia. Las crónicas indican que el núcleo de la élite gobernante estaba formado por una decena de linajes reales que descendían de los reyes-ancestros cuya memoria ha sido conservada. Cada familia noble nombraba miembros que se ocupaban de custodiar el cuerpo momificado del ancestro común, de alimentarlo, vestirlo y atenderlo durante ceremonias anuales. Asimismo, cada linaje poseía la propiedad exclusiva de la memoria de su fundador (Discurso, 1920 [1543-1608]: 3), de tal modo que solo los especialistas que pertenecían a la parentela del rey podían componer y narrar sus hazañas. Inmediatamente después de la muerte de un Inca, los miembros influyentes de su linaje se reunían para determinar si el difunto merecía que sus hechos fueran recordados. Si la respuesta era afirmativa, convocaban a sus khipukamayuq para registrar un canto «que en ellos [los reyes] fuesen muy alabados y ensalçados, de tal manera que todas las jentes se admirasen en oyr sus hazañas y hechos tan grandes» (Cieza de León, 1996 [1554]: cap. $\mathrm{XI}, 28)$. Si, al contrario «entre los reyes alguno salía remiso, cobarde, dado a biçios y amigo de holgar sin acrecentar el señorío de su ynperio, mandaban que destos tales oviese poca memoria o casi ninguna» (Cieza de León, 1996 [1554]: cap. XI, 28). Así, estos cantares épicos no eran informes exhaustivos del pasado sino que ofrecían más bien una selección parcial de los sucesos realizados por algunos individuos. Estaban estrechamente relacionados con las pretensiones, y eventualmente la vanidad, de los grupos de corporación incas que, por añadidura, competían periódicamente por los cargos de autoridad. Estos conflictos entre linajes estallaban con frecuencia en períodos de sucesión real. Por su investidura, el soberano tenía la prerrogativa de redistribuir los cargos de prestigio y de conceder a quienes deseaba acceso a mano de obra y recursos naturales suplementarios. Los individuos que tenían la buena suerte de apoyar al pretendiente victorioso recibían estos favores, lo que no tardaba en crear tensiones considerables dentro de la élite dirigente. Lo atestigua el conflicto fratricida que estalló tras la muerte de Huayna Cápac, durante el cual Atahualpa hizo ejecutar a la mayoría de los hijos, esposas y aliados de Huáscar que residían en el Cuzco. Ordenó también que los miembros influyentes del linaje de Tupac Yupanqui y la momia de este rey fueran eliminados porque habían apoyado activamente a Huáscar. Por último, los capitanes de Atahualpa se apresuraron en matar a los khipukamayuq de esta descendencia e incendiaron sus registros. Pretendían así aniquilar la memoria de Tupac Yupanqui porque «de nuevo habían de comenzar (nuevo mundo) de Ticci Capac Inga, que ansí le Ilamaban a Ataovallpa Inga»(Discurso, 1920 [1543-1608]: 4; Sarmiento de Gamboa, 1988 [1572], cap. LXVII: 162-164).

Así, los relatos históricos incas sin duda fueron materia de disputas e instrumentos de legitimación antes de la era colonial. Gracias a la memoria de los khipus, las familias nobles reivindicaron sus derechos de obtener puestos de autoridad en base a su prestigiosa ascendencia o invocando el apoyo dado por sus antepasados a los reyes de antaño. Un linaje real desprovisto de su tradición histórica no solamente estaba privado de influencia política, sino que 
estaba también despojado de prestigio ritual puesto que los cantares épicos se enunciaban públicamente durante las festividades más importantes 3 . El recitador de cada linaje rivalizaba en ingenio y talento oratorio, exaltando las cualidades gubernativas y las hazañas militares de su antepasado. Como resultado, las composiciones estaban inevitablemente impregnadas de divergencias de opinión y de tensiones inherentes a las relaciones entre los grupos de parentesco real (Salomon, 1999: 84).

En vista de la dimensión política y exclusiva de los cantares épicos incas así como la diversidad de los medios narrativos utilizados por la élite, se vuelve necesario examinar las incoherencias de las crónicas no solamente como resultado de manipulaciones coloniales, sino también como indicio de testimonios que coexistieron de manera conflictiva desde la época prehispánica. A este enfoque se añade un último punto que también proviene de la distinción entre los diferentes planos enunciativos en los informes coloniales. De hecho, las crónicas combinan materiales de índole sociológico y descriptivo con elaboraciones narrativas procedentes de los cantares épicos como de los relatos sobre tablones. Los textos coloniales entreveran así varios géneros y hacen coexistir la enunciación de prescripciones y normas sociales -la descripción del matrimonio preferencialcon discursos reflexivos sobre estas normas —la narración de eventos que conducen a tal rey a no desposar a la cónyuge preferencial- . Las menciones contradictorias de las reglas de sucesión ilustran cómo estos dos tipos de enunciado pueden evocar realidades que no son necesariamente congruentes. Sobre este tema, hace tiempo que los etnohistoriadores concuerdan en estimar que los Incas no observaban un procedimiento institucionalizado (Rostworowski, 1960; Zuidema, 1962: 122-128; Duviols, 1979b; Pease, 1991 [1972]: 88, 107). Los relatos de la vida de cada Inca apoyan esta tesis ya que son numerosas las tomas del poder por la fuerza por parte de los hijos «ilegítimos» del soberano fallecido recientemente. A pesar de esto, entre los cronistas que relatan estos conflictos, muchos estipulan también que la función real tenía que corresponder al hijo mayor del Inca anterior (Betanzos 1987 [1551], Lib. I, cap. XVI: 78; Discurso, 1920 [1543-1608]: 12; Sarmiento, 1988 [1572], cap. XIV: 63; Fernández, 1963 [1571], T. III, cap. V: 80; Garcilaso, 1985 [1609], Lib. IV, cap. IX: 186-187). A fin de explicar estas contradicciones, la mayoría de los estudios argumentan que los cronistas desvirtuaron las declaraciones de sus interlocutores indígenas y atribuyeron a los Incas una regla sucesoria propia de las monarquías europeas pero extraña al Tawantinsuyu. Sin embargo, la existencia de un modelo ideal de continuidad dinástica no significa necesariamente que, en la arena política, los actores históricos se hayan adherido inmutablemente a sus principios. En la época de la conquista española hubo numerosas violaciones a las reglas de sucesión en las cortes europeas. La tentación de transgredir era tanto más fuerte cuanto más

3 Las fuentes coloniales documentan al menos tres celebraciones durante las cuales estos cantares se ejecutaban en tiempo inca: los segundos funerales reales (purukaya), la investidura de un nuevo soberano y el ritual de iniciación masculina para que, según los cronistas, los iniciados se dediquen a imitar la fuerza de espíritu y las hazañas de su antepasado. 
importante era el interés, y ¿qué interés sería más atractivo que ganar la borla de Sapa Inca? Así, el hecho de considerar el principio de primogenitura como una prescripción inca no es incompatible con el tema de algunos relatos dinásticos que ponen en escena individuos que transgreden el modelo edificado por sus antepasados. Como ya se observó, estas configuraciones coexisten en varias crónicas entre las cuales se encuentra la obra de Betanzos, quien disponía de un acceso privilegiado a las tradiciones incas gracias a su matrimonio con una mujer de la antigua nobleza dirigente. Betanzos estipula que el heredero legítimo se llamaba piwi churi, que designaba al hijo mayor del rey con su esposa principal. Esta observación no le impide dedicar numerosos capítulos de su Suma y narración a la toma disidente del poder de Inca Yupanqui (véase también Cieza de León, 1996 [1554], cap. X: 25).

Así, la resolución de las contradicciones aparentes de la historia inca hace necesario, en primer lugar, distinguir los diferentes tipos de enunciado presentes en una misma crónica. Esta lectura de las fuentes primarias exige que nos desviemos provisionalmente del problema de la objetividad histórica de los relatos incas para interrogarnos sobre su finalidad. Exige también identificar en dichas fuentes las modalidades propias al discurso precolonial. Algunos trabajos recientes se han dedicado a esta tarea, procediendo a un análisis literario de las crónicas (Julien, 2000; Mazzotti, 2008). Empleo aquí una metodología similar en el tratamiento de un episodio singular de la historia inca, el del origen de las mitades del Cuzco a propósito del cual existen varias versiones contradictorias. El análisis textual comparativo de este corpus heterogéneo tiende a aislar las modalidades narrativas que caracterizan a cada variante y a sacar los datos sociológicos específicos que están asociados a cada una de ellas. Este trabajo consiste en restituir el marco narrativo original dentro del cual cada uno de estos datos tenía su significación. Lejos de recusar la pertinencia de los análisis historiográficos anteriores, este modo de lectura de las fuentes es complementario. No hay duda de que los intereses políticos de la colonización y las convenciones literarias de la España Moderna influyeron en parte en la elaboración de las crónicas. Sin embargo, estos factores no explican totalmente la amplia divergencia existente entre las narraciones acerca de la historia inca. El número y la riqueza narrativa de los textos coloniales sobre el origen de la división dualista del Cuzco permiten un estudio comparativo que ilustra esta metodología. De hecho, más allá de sus diferencias formales, estos relatos se oponen en lo que se refiere a la representación de la continuidad dinástica que se resume a elegir entre respetar o transgredir las reglas de sucesión.

\section{LAS MITADES: ORIGEN Y PRINCIPIOS}

Las fuentes coloniales registran diferentes relatos de extensión variable sobre la creación de las mitades incas, más unos datos sociológicos sobre su composición. Indican que cada una de estas divisiones espaciales fue ocupada por un cierto número de parentelas que poseían responsabilidades rituales asociadas a su 
pertenencia a una mitad. Las escasas explicaciones sobre la repartición de los cargos ceremoniales indican que cada mitad comprendía cinco ayllus comunes y cinco linajes reales 4 , a los cuales la literatura científica moderna llama «panacas» aunque esta designación es problemática5 ${ }^{5}$ (Cobo, 1964 [1653], Lib. XIII, cap. XIII-XVI: 169-186; Molina, 1989 [1575]: 74-75). Además, estos grupos de parentesco seguían una estricta jerarquía dentro de su mitad y las mitades mismas eran asimétricas: los miembros de Hanan Cuzco poseían rangos más elevados y funciones más prestigiosas que los de Hurin $\mathrm{Cuzco}^{6}$. Esta dimensión dualista de desigualdad social se extendía a la organización interna de las mitades ya que ellas también estaban divididas en parcialidades Alta y Baja, generando así cuatro sectores asimétricos aplicables a los suyus. La mitad Alta incluía las divisiones del chinchaysuyu y antisuyu, mientras que la mitad Baja comprendía los sectores menos prestigiosos del qullasuyu y kuntisuyu. Estas cuatro divisiones obedecían a su vez a un jefe principal, de tal modo que cada mitad estaba administrada por dos dirigentes de estatus desigual. Los títulos respectivos de estos dignatarios eran comparables a los de cacique principal y segunda persona en la época colonial, lo que significaba que el dirigente de la subdivisión Hanan poseía el poder de tomar decisiones cuando los intereses de la mitad en su totalidad estaban en juego (Rostworowski, 1977; 1988: 189-194).

A estos principios de estratificación social se sumaba una oposición generacional: los linajes reales de la parte Baja descendían de los soberanos tradicionalmente asociados a los primeros tiempos de la monarquía quienes no ampliaron su dominio de influencia más allá de la región del Cuzco. Por lo que se refiere a las parentelas de la parte Alta, las crónicas nos dicen que descendían de los Incas quienes emprendieron una política activa de conquista y extendieron el imperio a su grandeza final7. Por último, los diccionarios coloniales asocian el término hanan a lo que se sitúa arriba y al exterior, mientras hurin — probablemente urin en su

4 Mientras los informes coloniales sobre las celebraciones incas mencionan la participación ritual de diez parentelas nobles, Rostworowski (1983: 141 y ss.) sostiene que fueron dieciséis en total. La mayoría de las crónicas coinciden en listar diez a doce linajes reales: el Tumibamba panaca ayllu asociado a Huayna Capac no aparece en todas las fuentes, mientras dos grupos de descendencia son relacionados al Inca Pachacuti Yupanqui: el Iñaca panaca ayllu y el Hatun ayllu.

5 Aunque se empleó el término «panacas» en publicaciones anteriores para designar a los linajes reales incas, hoy nos parece necesario reconsiderar este uso. Francisco Hernández Astete (2008) subrayó que no existen materiales documentales de la época colonial que sostienen la designación de panacas por las parentelas nobles. En un reciente artículo, César Itier (2011) reconsidera el uso de esta palabra en la historiografía y pone en evidencia que «panaca» fue usado inicialmente para designar a un gobernador o mayordomo. Asociado al término «ayllu» con el cual aparece frecuentemente en las genealogías reales, «panaca» sería el título que designaba al «capitán de linaje».

6 La distribución de los cargos entre las parentelas durante la festividad de citua (sitwa) y en la organización del sistema de los ceques (seqe) sugiere una indudable correlación entre estratificación social y rangos rituales (Molina, 1989 [1575]: 74-75; Cobo, 1964 [1653], Lib. XIII, cap. XIII-XVI: 169-186).

7 Encontramos relaciones de oposición similares en otras organizaciones dualistas de los Andes prehispánicos y coloniales, siendo el caso más conocido el de los Huari (agricultores) y de los Llacuaz (pastores de la puna) en la región de Huarochirí (Duviols, 1973). 
forma original— designa lo que se encuentra adentro8 (Arellano Hoffmann, 1998; Cerrón-Palomino, 2002).

Mientras estos datos descriptivos concuerdan en las crónicas, los relatos sobre el origen de Hanan y Hurin no coinciden a propósito de la identidad del rey que tuvo la iniciativa de esa división dualista —al menos cuatro personajes son mencionados - ni a propósito de su repercusión social. Algunos textos exponen también dos variantes posibles del relato. Tres de ellos atribuyen la creación de las mitades a Inca Roca, tradicionalmente considerado como el sexto rey de la dinastía y el primer rey procedente de Hanan Cuzco (Sarmiento, 1572; Cabello de Balboa, 1586; Murúa, 1590-1602). El primer escrito, encargado por el virrey Francisco de Toledo durante su mandato (1569-1581), es un ejemplo notorio de materiales reunidos para favorecer la tarea colonial del recién investido administrador de la Corona, denunciando la tiranía e ilegitimidad del dominio inca. Es también un documento histórico importante porque combina las voces de varios miembros de la nobleza inca y de la élite provincial que fueron consultados y, después, convocados para confirmar la autenticidad de sus informes. En cuanto a las obras de Cabello y Murúa, comparten varias similitudes debidas probablemente a la utilización de una fuente común: el manuscrito perdido del Padre Cristóbal de Molina, quien participó también en las encuestas de Toledo durante el mismo período que Sarmiento (Rowe, 1985; Julien, 2000: 166-185; Álvarez-Calderón, 2007). Así pues, no es sorprendente que estos tres textos describan de manera similar eventos notables de la historia de los Incas. Relatan que Inca Roca, al constatar que todos los reyes pasados pertenecían a la parte Baja de la ciudad, decretó que en adelante los soberanos debían establecerse en la parte Alta. Cabello y Murúa explican que ordenó esta división para gobernar con más eficacia; Cabello añade que el rey impuso esta estructura a todas las ciudades del imperio. Además, los tres cronistas evocan el episodio de manera sumaria. En su texto, la partición del Cuzco aparece como un hecho ordinario sin otra incidencia que el desplazamiento espacial de la descendencia de los futuros reyes. Se inscribe naturalmente dentro del relato sucinto de la vida de Inca Roca que consta de un breve retrato psicológico del soberano9 ${ }^{9}$, de los nombres de sus descendientes cercanos, y de los pueblos que conquistó sin detallar las circunstancias de sus victorias. Solo Sarmiento indica que fue informado de otro relato al referir que «en tiempo de Pachacuti, fueron estos ayllus reformados, y por esto dicen algunos que entonces fueron hechos estos dos bandos tan celebrados en estas partes» (Sarmiento, 1988 [1572], cap. XIX: 72).

8 César Itier nota que ambas formas $<$ hurin $>$ y $<$ urin $>$ se encuentran en las fuentes coloniales aunque el segundo empleo es más frecuente en los textos quechuas. Esta ocurrencia sugiere que la $\langle\mathrm{h}\rangle$ de la primera grafía es ornamental. Así, urin está emparentado con ura-, «bajar», y sería el resultado de una monoptongación de la segunda sílaba de uray- («bajo») a la cual se adjuntó el posesivo de la tercera persona -n para dar el sentido de «parte de abajo» (comunicación personal).

9 «Mostró bríos y valor», su reinado fue «una quieta, pasifica, y felice temporada, donde paso el discurso de su vida ocupado en fiestas y bayles», «fue grave y apacible, y señoreó en gran sosiego», «Fue dadivoso y magnifico» (Sarmiento, 1988 [1572], cap. XIX: 71; Cabello, 1951 [1586], Lib. III, cap. XIII: 291; Murúa, 2001 [1590-1602], Lib. I, cap. XIII: 58-59). 
Contrariamente a los tres autores mencionados, Garcilaso de la Vega y el Padre Cobo afirman que las mitades existían desde la edificación del Cuzco por los fundadores del linaje real, Manco Capac y su hermana-esposa. El largo capítulo que Cobo dedica a las diferentes versiones de este relato revela que consultó a varios autores, incluso a Polo de Ondegardo (a quien menciona) y a Garcilaso de la Vega. Así, es posible que algunos detalles originales de su descripción de las mitades provengan del texto perdido de Polo de Ondegardo, o que hayan sido recolectados durante las entrevistas que Cobo realizó en la década de 1610 con algunos nobles incas. Su relato de la fundación de Hanan y Hurin se inspira directamente de la obra de Garcilaso, quien ofrece el primer ejemplo conocido de esta versión. Aunque el relato del historiador mestizo es más enfático y pródigo en detalles que el de Cobo, los dos textos siguen el mismo desarrollo narrativo. Cuentan que la pareja de migrantes, Manco Capac y su esposa, se detuvieron a la entrada de un valle fértil, sobre el cerro Huanacauri. De allí, «El príncipe fue al septentrión y la princesa al mediodía. A todos los hombres y mujeres que hallaban por aquellos breñales les hablaban y decían cómo su Padre el Sol los había enviado del cielo para que fuesen maestros y bienhechores de los moradores de toda aquella tierra» (Garcilaso, 1985 [1609], Lib. I, cap. XVI: 39). Impresionados por la compostura y los adornos de los advenedizos, la gente de la región construyó las primeras casas del Cuzco.

Los que atrajo el Rey quiso que poblasen a Hanan Cuzco, y por esto le llaman el alto, y los que convocó la reina que poblasen a Hurin Cuzco, y por eso le llamaron el bajo (...) Y mandó que entre ellos hubiese sola una diferencia y reconocimiento de superioridad: que los del Cuzco alto fuesen respectados y tenidos como primogénitos, hermanos mayores, y los del bajo fuesen como hijos segundos (Garcilaso, 1985 [1609], Lib. I, cap. XVI: 40; véase también Cobo, 1964 [1653], Lib. XII, cap. III: 63).

Garcilaso y Cobo se distinguen también de los otros cronistas por su descripción original de la descendencia de Manco Capac que contradice el informe estandarizado de la genealogía real y de la repartición de sus linajes reales. Cobo nos dice:

Manco Capac, que como cabeza y tronco de ambas parcialidades de Hanan Cuzco y de Hurin Cuzco, no entraba en la división dellas, los demás reyes unos fueron de Hanan Cuzco y otros de la de Hurin Cuzco (Cobo, 1964 [1653]: Lib. XII, cap. IX, 72).

Concuerda entonces con José de Acosta quien, probablemente extrayendo de los escritos de Polo de Ondegardo, afirma que Manco Capac «dio principio a dos linajes principales de ingas: unos se llamaron Hanan cuzco y otros Urincuzco» (Acosta, 1962 [1590], Lib. VI, cap. XX: 306). Garcilaso evoca el mismo hecho cuando explica la organización de la nobleza dirigente:

Los Incas de la sangre real, divididos por sus aillus, que es linajes, que aunque todos ellos eran de una sangre y de un linaje, descendientes del Rey Manco Capac, con todo eso hacían sus divisiones de descendencia de tal o tal Rey (...) Y esto es lo que los historiadores españoles dicen en confuso, que tal Inca hizo tal linaje y tal Inca otro linaje Ilamado tal, 
dando a entender que eran diferentes linajes, siendo todo uno, como lo dan a entender los indios con llamar en común a todos aquellos linajes divididos: Capac Aillu, que es linaje augusto, de sangre real (Garcilaso, 1985 [1609], Lib. VII, cap. IX: 104-105).

El sistema de linajes descrito por Garcilaso y Cobo, similar al de Acosta, se opone así a la genealogía linear propuesta por Sarmiento, Cabello y Murúa (fig. 1).

\begin{tabular}{|c|c|c|c|c|}
\hline \multicolumn{2}{|c|}{ Corpus Cabello, Sarmiento, Murúa } & \multicolumn{3}{|c|}{ Corpus Garcilaso, Cobo } \\
\hline \multirow{4}{*}{ HURIN } & $\begin{array}{l}\text { Manco Capac } \\
\text { Sinchi Roca }\end{array}$ & \multicolumn{3}{|c|}{ Manco Capac } \\
\hline & & Sinchi Roca & 1 & Inca Roca \\
\hline & Lruquir rupanqui & 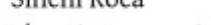 & 1 & ma kuca \\
\hline & Mayta Capac & Lluqui Yupanqui & ! & Yahuar Huacac \\
\hline & Capac Yupanqui & Mayta Capac & 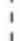 & Viracocha Inca \\
\hline & Inca Roca & Capac Yupanqui & 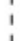 & Inca Yupanqui \\
\hline \multirow{5}{*}{ HANAN } & Yahuar Huacac & & 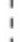 & Tupa Inca \\
\hline & Viracocha Inca & & ! & Huayna Capac \\
\hline & Inca Yupanqui & & $\vdots$ & \\
\hline & Tupa Inca & HURIN & 1 & HANAN \\
\hline & Huayna Capac & & & \\
\hline
\end{tabular}

Figura 1 - Modelo de la genealogía inca según dos grupos de crónicas

A pesar de su singularidad, los datos registrados por Garcilaso y Cobo se vuelven inteligibles cuando se les compara con un último corpus de relatos que atribuye la creación de las mitades sea a Pachacuti Yupanqui o a Tupac Yupanqui. Tres de estos textos, anotados por Las Casas (1562-1564), Román y Zamora (1575) y Gutiérrez de Santa Clara (c. 1590), son transcripciones casi uniformes. Solo el último atribuye la división bipartita a Tupa Yupanqui mientras que los dos primeros la atribuyen a Pachacuti. No se sabe con certeza la razón de esta similitud. Ya que el fenómeno de la copia es común en esta época, es posible que los tres utilizaran una fuente común. Sin embargo, el caso de Gutiérrez es singular y puede ser que haya recogido su relato en un contexto independiente de los otros dosio.

A este conjunto de versiones se añade la de Juan de Betanzos (1551) pues, aunque su enunciado es diferente, tiene en común el hecho de utilizar el lenguaje del parentesco para describir la organización dualista. Asimismo, todos inscriben la creación de Hanan y Hurin dentro de un ciclo narrativo de tipo épico. Ese

10 Las Casas y Román nunca residieron en el Perú, pero el primero mantuvo una correspondencia con algunos informantes in situ, entre otros el dominico Domingo de Santo Tomás. Sacó también materiales de las relaciones de Xerez-Estete (1534), Cieza (1554) y Bartolomé Segovia (1553). La obra de Román se inspira ampliamente de la Apologética historia sumaria de Las Casas, lo que explicaría la similitud de sus relatos. En cuanto a Gutiérrez, recogió varios pasajes de la crónica de Román (Pärssinen, 1992: 58-67), pero eso no explica que él atribuya la creación de las mitades a un rey diferente. Gutiérrez consultó también a Zárate, Gómara, Cieza y Fernández, pero ninguno de ellos menciona el relato que nos interesa. 
cuenta cómo el hijo menor de un rey añoso ganó la estima de los cuzqueños rechazando al ejército de los chancas, una etnia rival que se preparaba para atacar la ciudad. A raíz de esta victoria, el muchacho fue nombrado Inca, usurpando así la borla real que correspondía a su hermano mayor, Inca Urco. Inmediatamente después de su coronación, el vencedor de los chancas emprendió la distribución a sus aliados de tierras arables de los alrededores del Cuzco. A continuación, reformó el calendario ritual, construyó un templo en honor al dios que lo había protegido durante la batalla, y lo colocó a la cabeza de las otras divinidades. Por fin, ordenó la reconfiguración social y espacial del Cuzco según un modelo dualista asimétrico dentro del cual los grupos de parentesco fueron organizados de manera jerárquica. Los relatos nos dicen que esta reorganización fue impuesta porque el rey deseaba facilitar la distribución de las tareas comunitarias. También quiso crear un paralelo entre los ayllus del Cuzco para estimular la competencia de modo que cada uno se superase en la realización de estas faenas. Este marco narrativo es muy ajeno al primer corpus de relatos que describe la creación de las mitades como un evento casi anodino que no perturba la continuidad dinástica, ni engendra explícitamente un sistema de estratificación social. Las Casas, Román y Gutiérrez dicen que, una vez investido, el rey partió la ciudad en dos y dividió Hanan Cuzco en cinco barrios:

Al uno y principal nombró Capac Aillo, que quiere decir «el linaje del Rey»; con éste juntó gran multitud de gente y parte de la ciudad, que fuesen de aquel bando. Al segundo llamó Iñaca panaca; el tercero, Zucso panaca; el cuarto, Auca illi panaca; el quinto, Vicaquirau panaca; a cada uno de los cuales señaló su número grande de gente, y así repartió por bandos toda la ciudad. Del primer barrio o bando hizo capitán a su hijo el mayor y que le había de suceder en el reino; el segundo y tercero señaló a su padre y descendientes por la línea transversal; el cuarto a su agüelo y descendientes también por la línea transversal; el quinto, a su bisagüelo, por la misma línea.

Asimismo la parte y bando segundo y principal de la ciudad, que llamó de Rurincuzco, barrio de abajo del Cuzco, subdividió en otras cinco partes o parcialidades: a la primera llamó Uzcalmaita, y déste hizo capitanes a los descendientes del segundo hijo del primer rey inga; a la segunda nombró Apomaitha, de la cual constituyó capitán y capitanes al segundo hijo y descendientes del segundo inga; a la tercera parcialidad o bando puso nombre Haguaini, del cual nombró por capitán y capitanes al segundo y descendientes del tercero inga; al cuarto barrio nombró Raurapanaca, cuya capitanía encomendó al segundo hijo y descendientes del cuarto inga; al quinto barrio llamó Chimapanaca, y dióle por capitán y capitanes al segundo hijo y sus descendientes del quinto inga (Las Casas, 1909 [1562-1564], Lib. III, cap. CCLI: 581; Román y Zamora, 1897 [1575], Lib. II, cap. XI: 25-26; Gutiérrez, 1963-1964 [c. 1590], cap. L: 214).

Varios datos se destacan de esta descripción. En primer lugar, corrobora las informaciones de Garcilaso y Cobo a propósito del Qhapaq Ayllu, ya que indica 
que este nombre significaba «linaje real» y designaba la más prominente y prestigiosa de las familias nobles. Precisa también que la responsabilidad de este linaje correspondía al hijo mayor del Inca quien era destinado a heredar el título de soberano. Confirmaba así que la sucesión real se efectuaba idealmente por la regla de primogenitura masculina. Segundo, el marco temporal que estructura la división Hanan/Hurin en este relato no se resume simplemente a la oposición entre los primeros soberanos versus los soberanos más recientes, como es el caso en las narraciones que atribuyen la formación de las mitades a Inca Roca. Aquí, las parentelas reales de la parte Alta están organizados a lo largo de una línea recta a partir de la posición genealógica del Inca vivo, quien es el que reorganiza jerárquicamente los grupos de descendencia cuando accede al poder. El grado de proximidad de estos linajes, respecto al inca reinante, determina su posición jerárquica dentro de esta estructura, de tal modo que se tiene aquí un sistema de estratificación social basado en los lazos de parentesco. El mismo principio rige la organización jerárquica de las parentelas dentro de la parte Baja, salvo que esta se articule a partir de un referente genealógico diferente, siendo este el primer rey de la dinastía. La formación de los linajes de la parte Baja se funda sobre un referente fijo, es decir, el antepasado común de todos los soberanos y se enmarca en un pasado ancestral. En contraste, la organización de los grupos de parentesco de la parte Alta se elabora a partir de la posición genealógica del Inca vivo en una temporalidad que asocia un pasado y un futuro cercanos (fig. 2).

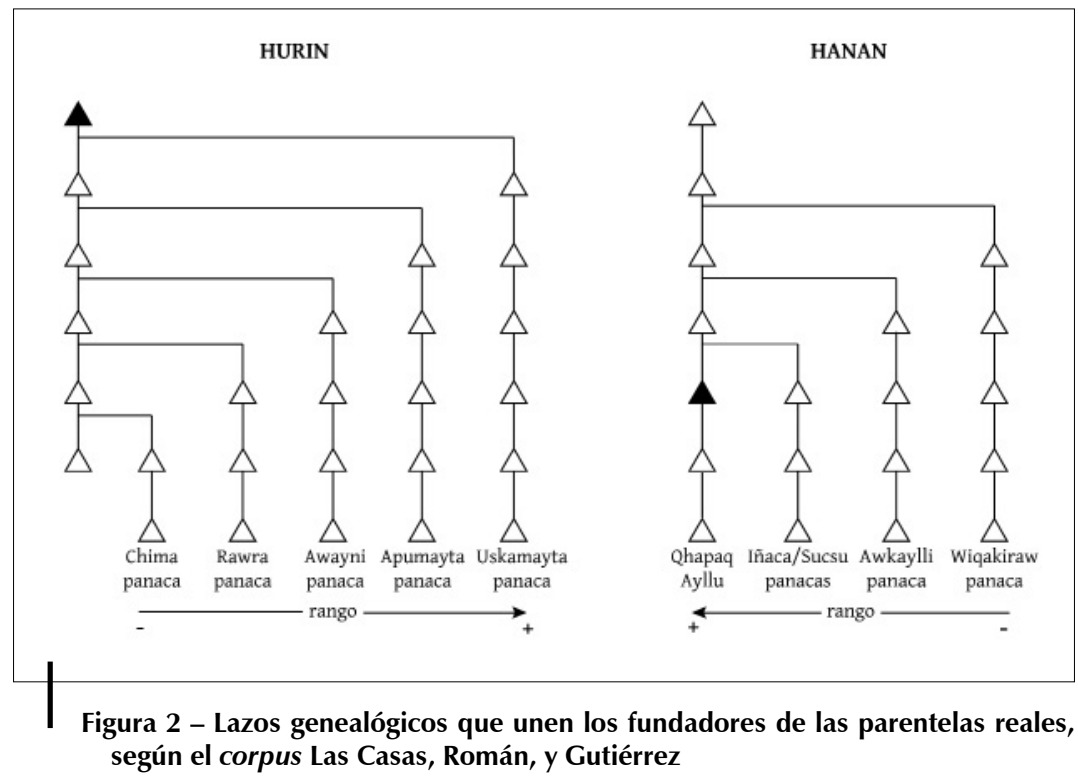

La representación esquemática de los lazos de parentesco que unen a los capitanes de los linajes de cada mitad revela claramente que un mismo principio de ordenamiento rige la organización jerárquica de Hanan y Hurin. Sin embargo, el relato de Las Casas, Román y Gutiérrez singulariza la estructura interna de cada 
bando empleando dos fórmulas distintas para expresar esa regla. En lo que se refiere a la parte Alta, subraya el lazo de descendencia directa que existe entre el Inca reinante y los capitanes de linajes, los cuales son su hijo, su padre, su abuelo y su bisabuelo. En cambio, refiriéndose a la parte Baja, acentúa las líneas colaterales a través de la evocación recurrente del segundo hijo de los reyes difuntos a la cabeza de las parentelas, de tal manera que la relación colateral (Hurin) se opone aquí al parentesco en línea recta o filiación (Hanan). Esta sutilidad discursiva adquiere un sentido pleno cuando se compara este relato con la última versión conocida de la creación de las mitades apuntada por Betanzos.

Como Las Casas, Román y Gutiérrez, Betanzos cuenta en detalle la guerra que el hijo menor de un rey displiscente ganó contra el ejército Chanca que había venido a conquistar el Cuzco. El muchacho, llamado Inca Yupanqui, consigue movilizar a algunos parientes lejanos para combatir a los invasores a pesar de que su padre había huido de la ciudad con su hijo mayor y sus altos dignatarios. Después de numerosos enfrentamientos, Inca Yupanqui derrota a los chancas gracias al apoyo de estos aliados y a la intervención milagrosa de una tropa de guerreros de piedra (purun awqa) enviados por un dios protector. Después de su victoria, el joven se establece en el Cuzco donde emprende una serie de reformas administrativas y religiosas antes de aplicarse a la reorganización de la ciudad. En este último proyecto, Inca Yupanqui reúne a sus más fieles compañeros de armas a fin de retribuirlos y les revela un pequeño modelo de barro que representaba el Cuzco. En este, designa a cada uno un distrito particular que ellos y sus descendientes han de poblar en adelante. De igual manera que el relato precedente, «de las casas del sol para arriba todo lo que tomaban los dos arroyos hasta el cerro do agora es la fortaleza dio e repartió a los señores más propincuos deudos suyos e descendientes de su linaje por línea recta hijos de señores de señoras de su mesmo deudo e linaje» (Betanzos, 1987 [1551], Lib. I, cap. XVI: 75). Mandó también que la parte Baja fuera poblada por los «hijos bastardos de señores aunque eran de su linaje los cuales habían habido en mujeres extrañas de su nación e de baja suerte» (Betanzos, 1987 [1551], Lib. I, cap. XVI: 75). Fue en Hurin Cuzco que establece a los hombres de su parentela lejana llamados Apu Mayta, Vicaquirau y Huaranga Quillescachi, quienes le secundaron en la guerra contra los chancas. Betanzos añade que estos individuos eran wakcha quncha, es decir «deudos de pobre gente e baja generación» (Betanzos, 1987 [1551]: Lib. I, cap. XVI, 76). Quncha se aplica precisamente a los hijos (de ambos sexos) de la hermana/prima (pana) de un hombre11. En cuanto a wakcha, su significado (pobre) se opone a qhapaq (poderoso, rico, opulento) que es el término que designa el linaje real a la cabeza de Hanan Cuzco, el Qhapaq Ayllu. Wakcha significa también «huérfano» y es interesante notar que actualmente se aplica a personas indigentes que no están insertadas en una red de parentesco suficientemente extensa para pretender acceder a riquezas en el sistema redistributivo andino (Spalding, 1974: 68; Isbell,

11 «Y así Concha es el sobrino, o sobrina de solos tíos varones ora sean hermanos o primos de su madre» (González Holguín, 1842 [1607]: 212). 
1978: 76-78). El relato de Betanzos coincide así con los datos del corpus Las Casas, Román y Gutiérrez porque todos asocian Hanan Cuzco con los ascendientes y descendientes en línea recta del Inca reinante, mientras que identifican Hurin Cuzco con los parientes lejanos de este Inca, tanto del punto de vista filial como temporal. Estos relatos se distinguen del corpus Sarmiento, Cabello y Murúa sobre dos puntos fundamentales. Por una parte, emplean el idioma del parentesco para explicar los principios de organización que rigen la división dualista y asimilan de hecho la oposición Hanan/Hurin a una distinción entre parientes cercanos y parientes lejanos. Por otra, articulan esta configuración social en torno a la posición jerárquica de dos individuos: el Inca reinante y el antepasado de la dinastía. Los relatos de Sarmiento, Cabello y Murúa, por el contrario, insisten sobre la continuidad genealógica que habría unido a los soberanos de las dos mitades y no asocian en ningún caso la organización dualista del Cuzco a un sistema de estratificación social.

Una sola divergencia sobre el estatus de los individuos Hurin parece oponer el texto de Betanzos al corpus Las Casas, Román y Gutiérrez. Aunque todos coinciden en asociar Hanan a los miembros del linaje real por filiación, Betanzos afirma que Hurin reúne la prole de los Incas con sus esposas extranjeras, mientras el segundo corpus identifica la misma mitad con la descendencia de los hijos segundos/ menores de los reyes. En realidad, esa contradicción no es sino aparente pues el estatus de los hijos ilegítimos o bastardos — para recuperar las formulaciones de los cronistas - estaba estructuralmente asimilado al de los hijos menores del Inca. En efecto, la oposición de mitades distingue los wakcha quncha (Hurin) por una parte, y los hijos del rey con su esposa principal (Hanan) por la otra. Ahora bien, estos últimos se llamaban piwi churi, lo que significa «primogénito» o «mayor» (González Holguín, 1952 [1608]: 545). Asimismo, la reina y señora principal se nombraba piwi warmi, lo que quiere decir «esposa primogénita», y tenía que pertenecer a la línea real «sin que en ella hubiese raza ni punta de wakcha quncha» (Betanzos, 1987 [1551], Lib. I, cap. XVI: 78). Las crónicas concuerdan en decir que era idealmente una hermana o prima hermana del Inca; en otras palabras, su pariente femenina más cercana. Así, las oposiciones dualistas del sistema de mitades no se resumían únicamente a una serie de contrastes simbólicos. Los miembros Hanan estaban investidos de los estatus más prestigiosos porque pertenecían a la línea real principal (Qhapaq Ayllu) por ambos padres. Eran hijos «legítimos» o «mayores» que se oponían a los hijos «segundos» nacidos de un padre noble y de una madre extranjera. Garcilaso evoca la misma oposición estructural cuando afirma que la gente del Cuzco Alto debía ser respetada y considerada como hermanos mayores, mientras los de la parte Baja eran tratados como hermanos menores.

El sistema de mitades fue una estructura de organización jerárquica del grupo de descendencia basada en la oposición binaria entre hijo mayor e hijo menor. Los primeros fueron qhapaq, es decir, opulentos y de ascendencia real de padre y madre, mientras los segundos fueron wakcha quncha o pobres y huérfanos, hijos de señoras sin ascendencia rica. Los textos de Las Casas, Román y Gutiérrez superponen a estas categorías una oposición en el modo de afiliación: los primeros designan a parientes en línea recta, mientras los segundos están asociados a 
relaciones colaterales. Ahora bien, este esquema de oposición es coherente con el principio de estratificación social descrito en este último corpus donde el rango de los individuos está determinado por el grado de proximidad generacional que les separa del antepasado común, sea el Inca reinante o el antepasado apical. En una sociedad segmentada según este principio, todos los miembros son teóricamente parientes en virtud de su afiliación al fundador del grupo social. Su estatus depende del grado de proximidad que les une a esta figura: cuanto más alejados de él, más inferior es su rango. Así, a nivel del núcleo familiar, un hijo mayor posee un rango superior al de sus hermanos menores porque está más cerca que ellos de la esencia divina del fundador. Por las mismas razones, la descendencia del hijo mayor será de estatus superior a la de su hermano menor. La primogenitura es pues una incidencia lógica de este sistema. A nivel de la sociedad, el mismo principio rige la composición del grupo de descendencia que puede subdividirse en varios linajes descendientes de los hijos del antepasado apical. Asimismo estas ramificaciones están ordenadas en orden jerárquico por el grado de proximidad generacional de su fundador respectivo al creador del grupo social. El esquema de este modelo presenta una línea principal (o mayor) procedente del antepasado común a partir del cual emanan las ramas menores de rangos decrecientes, de tal manera que A es superior a B, la misma que es superior a C, etc. (fig. 3).

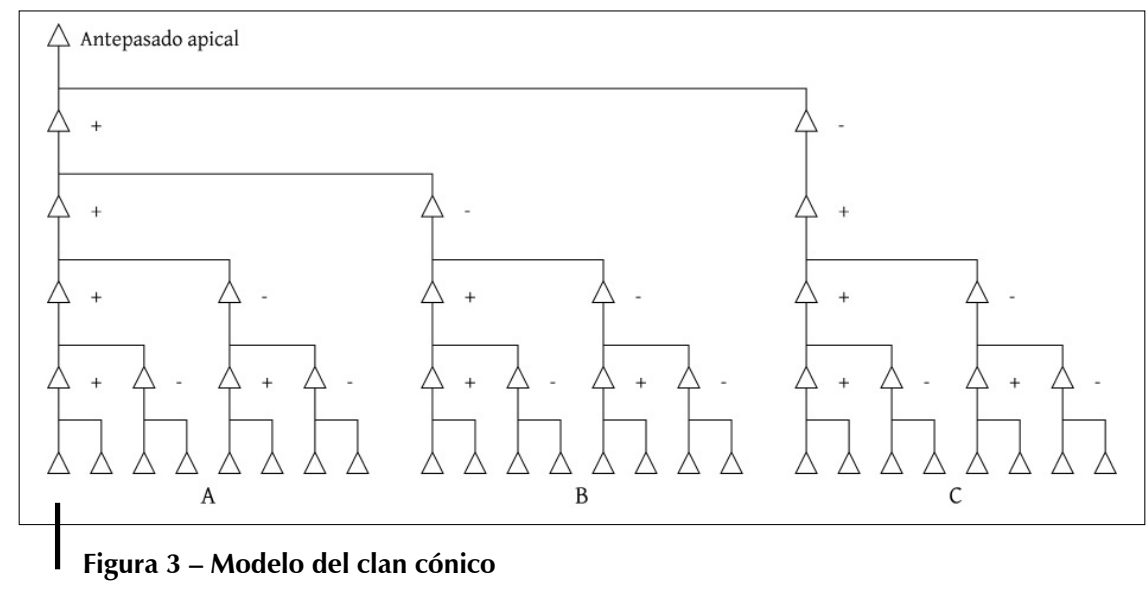

A partir de Sahlins (1958)

Esta representación coincide con la descripción del grupo de descendencia inca que hacen los relatos que hemos analizado. Garcilaso y el corpus Las Casas, Román y Gutiérrez identifican el Qhapaq Ayllu con el linaje real principal a la cabeza del cual estaba el Inca reinante12. Idealmente, esta línea estaba compuesta de la descendencia directa y legítima del fundador. Poseía ramas cadetes formadas por

12 Aunque sus conclusiones divergen, Seler (1894), Valcárcel (1925), Cunow (1929), Zuidema (1986) y recientemente Hernández Astete (2008) proponen que el Qhapaq Ayllu fue el linaje real principal del cual descendía el Inca reinante. 
los hijos llamados menores o ilegítimos, nacidos de la unión de los soberanos con sus esposas secundarias o extranjeras. Así, la mayoría de las fuentes precisan que estos linajes estaban dirigidos por «el hijo segundo» del Inca difunto. Cada una de estas parentelas invocaba a uno de los reyes descendientes de Manco Capac cuyas hazañas formaban la materia de los relatos históricos. El estatus de estas ramas dependía del grado de proximidad genealógica que unía su propio antepasado a la figura apical del grupo social. Garcilaso precisa, sin embargo, que todos estos «linajes divididos» eran Ilamados con el nombre común de Qhapaq Ayllu, de tal modo que las familias nobles formaban un solo y único grupo de descendencia.

Esta representación segmentaria del linaje real aclara también los informes de Cobo y Acosta quienes afirman que Manco Capac dio origen a los linajes de las dos mitades pero no pertenecía a ninguna de ellas. En realidad, ambos cronistas sugieren que Manco Capac era el ancestro apical del Qhapaq Ayllu y que solo las ramas cadetes del grupo entraban en el ordenamiento jerárquico de las mitades. Garcilaso también da una ilustración elocuente de esta organización en el capítulo final de sus Comentarios Reales. Evoca allí una probanza del año 1603 que le fue dirigida así como a Don Melchior Carlos Inca y a Don Alonso de Mesa, por algunos incas de sangre real quienes reclamaban entre otras cosas, su exención del tributo colonial. La carta listaba la ascendencia noble de cada litigante e iba acompañada de una pintura sobre tejido de aproximadamente $1 \mathrm{~m} 25 \mathrm{~cm}$ representando «el árbol real, descendiendo desde Manco Capac hasta Huaina Capac y su hijo Paullu» (Garcilaso, 1985 [1609], Lib. IX, cap. XL: 281). Garcilaso subraya que al lado de cada figura del Inca estaba inscrito el nombre de su linaje con esta designación: Qhapaq Ayllu, porque «este título es a todos en común, dando a entender que todos descienden del primer Inca Manco Capac. Luego ponen otro título en particular a la descendencia de cada Rey, con nombres diferentes, para que se entienda por ellos los que son de tal o tal Rey» (Garcilaso, 1985 [1609], Lib. IX, cap. XL: 282). Todas estas informaciones indican que las parentelas reales coexistieron desde la fundación de la dinastía, lo que es coherente con la composición demográfica homogénea de cada linaje al cabo de la época colonial (Julien, 1998).

Este modelo de organización segmentaria, conocido también con los nombres de clan cónico y ramaje, ha sido identificado en varias sociedades (Firth, 1957; Sahlins, 1958; Goldman, 1970; Hage \& Harary, 1996). Ya en 1949, Paul Kirchhoff había planteado la hipótesis que se aplicaba a la parentela inca. Lamentablemente, su contribución tuvo una recepción muy moderada porque las referencias de los cronistas a la primogenitura no eran consideradas auténticas. David Jenkins (2001) abrió de nuevo la discusión cuando propuso aplicar al grupo de descendencia cuzqueña un modelo teórico gráfico del clan cónico llamado depth first search tree. Pero su argumento ni siquiera examinaba la primogenitura como un principio estructural del ayllu real. A diferencia de estos estudios previos, el análisis comparativo de los relatos sobre el origen de las mitades revela que esta práctica fue una regla ideal de sucesión dentro de la nobleza y un principio fundamental de organización segmentaria que aclara 
el sistema de oposición entre Hanan y Hurin. Más bien, explica por qué las narraciones dinásticas se refieren siempre a las guerras de sucesión real como a enfrentamientos entre bandos. Cieza relata, por ejemplo, un sangriento intento de golpe de los Hurin Cuzcos contra Viracocha Inca quien había sido elegido soberano gracias al apoyo de señores Hanan Cuzcos a pesar de que era un sobrino del Inca difunto. La rebelión fue acaudillada por un hermano del rey precedente cuyo nombre, Capac, sugiere su afiliación al linaje real principal. Este quería apropiarse del título que le correspondía por derecho de nacimiento y que Viracocha Inca había usurpado con base en sus méritos (Cieza, 1996 [1554], cap. XXXVIII, XL, 112: 118-120). Betanzos y Sarmiento cuentan también que Huascar se apartó de «la parentela y linaje de los Hanan Cuzcos, porque de ellos era Atahualpa, el cual era un traidor» que aspiraba a hurtarle las insignias reales (Betanzos, 1987 [1551], Lib. II, cap. II: 209-210; Sarmiento, 1988 [1572], cap. LXIII: 151). En ambas ocasiones, las hostilidades oponían a hermanos o parientes de diferentes estatus que reivindicaban su legitimidad para reinar ya sea por su afiliación directa al linaje real principal, o por su valor y aptitud para reunir muchos aliados. Así, las fuentes coloniales se contradicen precisamente sobre la aplicación de la regla de primogenitura en tiempo prehispánico porque inicialmente los registros históricos de la élite inca estaban también en desacuerdo sobre este punto. Ahora bien, para aclarar los antagonismos que oponen el discurso sobre el pasado de la dinastía, se propone investigar las diferentes modalidades que caracterizan a cada grupo de relatos sobre el origen de las mitades.

\section{LA SUCESIÓN HEREDITARIA ES HISTORIA ANTIGUA}

Teóricamente, en un sistema segmentario como el de la nobleza inca, el linaje real solo puede reproducirse si se respeta la regla de primogenitura y el Rey se casa con una mujer de rango igual al suyo, siendo la candidata ideal su hermana biológica. Existe así una fuerte tendencia a la endogamia en la cumbre de la jerarquía de prestigio. El mantenimiento de tales preceptos, sin embargo, no es probable en la realidad de la arena política, especialmente en el seno de una sociedad que poseía pretensiones expansionistas. Las fallas de ese sistema surgían tras la muerte de un Rey, cuando las diferentes facciones de la nobleza se enfrentaban, a veces en un baño de sangre, para posicionar a su favorito en el poder. Las diferentes narraciones sobre la formación de las mitades del Cuzco resumen precisamente esta tensión entre, por una parte, un sistema dinástico idealmente basado sobre la perpetuación de la jerarquía de prestigio a través de reglas estrictas de transmisión de los estatus, y por otra, un sistema dinámico abierto a la nominación de un sucesor real que se hubiese revelado como el más apto para gobernar.

Estos relatos se diferencian en primer lugar sobre la identidad del Inca que creó las mitades. El corpus Sarmiento, Cabello y Murúa, que atribuye la división del Cuzco a Inca Roca, describe una dinastía que se perpetúa a través del respeto inmutable 
de las normas estructurales. No hace alusión ni a la asimetría de los estatus entre las mitades, ni a la organización jerárquica interna de cada una. Al contrario, Inca Roca crea Hanan y Hurin sin revolver el orden social preexistente. Más bien, este corpus establece una continuidad temporal directa entre los soberanos de las dos mitades, mientras en las obras de Las Casas, Román, y Gutiérrez los soberanos de la parte Baja se sitúan en un pasado ancestral sin lazo mensurable con los reyes de la parte Alta. La insistencia del primer conjunto de textos sobre la perpetuidad dinástica es tanto más significativa cuanto que las crónicas de Cabello y Murúa forman parte de un grupo de obras que describen la dinastía inca como una sucesión ininterrumpida de hijos mayores quienes invariablemente se casaron con su hermana biológica13. Su informe de la historia inca ofrece una visión armoniosa de las relaciones entre parentelas nobles, cada soberano engendrando a su muerte un linaje diferente del de su predecesor. Sarmiento explica en su capítulo sobre Inca Roca:

Es de notar que cada Inca hacía particular palacio en que vivir, no queriendo vivir el hijo en las casas que había vivido su padre, antes las dejaban en el estado que eran al fallecimiento del padre, con criados, deudos y ayllu y sus heredades (Sarmiento, 1988 [1572]: cap. XIX, 72).

Esta descripción niega la contemporaneidad de los linajes para subrayar la persistencia genealógica del grupo de descendencia real. Cabello y Murúa también describen los reinados de los unos a continuación de los otros de manera parsimoniosa, sin ventilar los estratagemas de conquista. Solo los nombres de cada provincia sometida y de cada pueblo sujetado están registrados meticulosamente. En estos relatos, las amenazas de rebelión proceden del exterior del Cuzco y no de los miembros de la élite dirigente que aspiraban al poder. En cuanto a Pachacuti Yupanqui, Cabello y Murúa lo presentan como el verdadero heredero legítimo de Viracocha Inca, mientras que Sarmiento explica que Inca Urco fue un hijo bastardo que su padre había nombrado sucesor, no por sus capacidades, sino porque quería mucho a su madre. Sarmiento cuenta también que los capitanes Apu Mayta y Vicaquirau, a quienes Betanzos había identificado como wakcha quncha, eran más bien hijos legítimos de Viracocha Inca. Además, en los capítulos sobre Inca Yupanqui, los mismos cronistas evocan la reedificación del Cuzco por este rey y la construcción de nuevas moradas para las divinidades, pero no hacen alusión a la división de mitades (Sarmiento, 1988 [1572], cap. XXV: 83; Murúa, 2001 [1590-1602], Lib. I, cap. XVII: 62; Cabello, 1951 [1586], cap. XIV: 298-299). Invierten así totalmente las relaciones de parentesco descritas en el corpus Las Casas, Román y Gutiérrez, lo que refuerza la continuidad genealógica y establece la imagen de una larga línea de reyes descendientes directamente del Sol desde tiempo inmemorial.

13 Este grupo abarca también a Diego Fernández (1571), de quien Murúa se aprovechó para escribir su obra y el Discurso sobre la descendencia y gobierno de los Incas (1543-1608). Esta última crónica comparte similitudes con la de Murúa, como por ejemplo su narración original de la venida de Manco Capac a la región de Cuzco. 
Contrastando con este marco descriptivo, los textos que atribuyen la división del Cuzco a un soberano reformista, sea Inca Yupanqui o Tupa Inca, lo describen como el hijo menor de un dirigente miedoso y viejo. El joven usurpa el título real a su hermano mayor, favorito de su padre y heredero legítimo, después de haber demostrado su aptitud para gobernar. Da prueba de su valentía eliminando el ejército Chanca gracias a la asistencia de un dios solar que se presenta como su padre y a la movilización de algunos wakcha quncha, es decir, miembros de las ramas cadetes del grupo de descendencia. Los relatos de los éxitos de este Inca contrastan vivamente su carácter con el de Inca Urco a quien describen como «cobarde, remiço, lleno de viçios y con pocas virtudes», «soberbio y despreciador de los demás» para los unos, «algo simple» para los otros; «era de tan poca honra que no quería que le estimasen y andava por las más partes de la ciudad beviendo; y desque tenía en el cuerpo una arroba y más de aquel brebaje, probacándose a gómito, lo lançava y sin vergüença descubría las partes vergonçoças y echava la chicha convertida en orina» (Betanzos, 1987 [1551], Lib. I, cap. VIII: 31-32; Cieza, 1996 [1554], cap. XLIII-XLIV: 128-131; Sarmiento, 1988 [1572], cap. XXV: 83). Los mismos relatos nos dicen que su hermano menor, por el contrario, era amado de todos porque era «mancebo muy virtuoso y afable en su conversación era hombre que hablaba poco para ser tan mancebo e no se reía en demasiada manera sino con mucho tiento y muy amigo de hacer bien a los que poco podían» (Betanzos, 1987 [1551], Lib. I, cap. VIII: 31). Este género narrativo opone el mayorazgo al mérito personal, exalta las cualidades del que trasciende las reglas sucesoras con el fin de perpetuar la soberanía del grupo de descendencia. Las proezas del hijo menor, su virtud moral y su relación personal con lo divino aseguraban que el imperio no cayera en manos de un dirigente disoluto quien gozaría únicamente de sus privilegios innatos sin participar en el ejercicio del poder.

Ahora bien, cuando un hijo menor o sea un wakcha quncha se apropiaba de las insignias reales, se posicionaba en vida a la cabeza del grupo de descendencia. Pero, al no ser el individuo de rango más alto, su toma de poder lógicamente acarreaba un cambio radical de la jerarquía de prestigio, afectando así la atribución de los estatus y de los cargos de autoridad. La anarquía podría desestabilizar el orden social si el nuevo Sapa Inca no recurría a dos estrategias de legitimación en su nueva posición: la ceremonia de elección divina y, una vez investido, la reordenación jerárquica de las parentelas reales en torno a su persona. Estos dos mecanismos de regulación son descritos precisamente en las obras de Las Casas, Román y Gutiérrez, así como en las crónicas que transcriben el relato épico del rey reformista Inca Pachacuti o Tupa Yupanqui. La elección divina de este príncipe ocurrió en dos fases. Primero, un dios de aspecto solar se le apareció al muchacho antes de su ascensión al poder y se presentó como su padre. Le aseguró que vencería a sus enemigos con su apoyo:

Vení acá hijo, no tengáis temor, que yo soy el Sol vuestro padre, y sé que avéis de sujetar muchas naciones; tened muy gran cuenta conmigo de me reverenciar y acordar os en vuestros sacrificios de mí (Molina, 1989 [1575]: 60). 
Una vez victorioso sobre los chancas, el muchacho ayunó e hizo ofrendas a su antepasado divino por muchas semanas, al cabo de las cuales un oficiante de alto rango consultó la voluntad divina examinando los pulmones de una llama sacrificada. La sanción divina significaba que el pretendiente podría ser consagrado «hijo del Sol» (intip churin) (Sarmiento, 1988 [1572], cap. XXIX: 93; Betanzos, 1987 [1551], Lib. I, cap. XVII: 83); es decir, el individuo más legítimo para portar la borla porque se había vuelto el descendiente más cercano de la fuente de fuerza vital (kamaq) del ayllu real que era el Dios Sol. De esta manera, el muchacho se volvió cabeza del grupo de descendencia inca.

La segunda estrategia de legitimación derivaba de esta reordenación porque el nuevo soberano vino a ser el nuevo referente genealógico a partir del cual el rango de los individuos fue determinado, relegando así el ancestro de la dinastía a un pasado lejano. El corpus Las Casas, Román y Gutiérrez cuenta que, una vez establecido, el hijo menor nombra a su futuro hijo mayor cabeza del Qhapaq Ayllu, la ramificación principal del sistema de linajes, y atribuye los estatus más altos a las líneas procedentes de sus ascendientes directos, formando así la división Hanan. Después, reúne en Hurin Cuzco a sus parientes más lejanos, asignándoles por lo tanto los estatus más bajos. Esta reordenación espacio-temporal y la nueva posición del soberano usurpador a la cabeza del grupo de descendencia real aclaran el significado del nombre pachakuti que toma por su investidura. Esta palabra significa literalmente «cambio de época y vuelco del espacio preexistente», lo que se refiere a la reconfiguración del sistema de rangos materializado en la geografía del Cuzco y basado en la distancia genealógica (temporal) con el jefe del linaje real. En este relato del origen de las mitades, todos los linajes son contemporáneos y constituyen las ramas menores del ayllu principal. De hecho, el corpus Las Casas, Román y Gutiérrez evoca precisamente un caso de usurpación del título real por un hijo ilegítimo que acarreó una nueva configuración jerárquica de las parentelas y la creación de mitades asimétricas. Así, los relatos épicos que narran las hazañas de los advenedizos de Hanan Cuzco invierten las oposiciones estructurales del modelo normativo descrito en las tradiciones registradas por Sarmiento, Cabello y Murúa.

Las divergencias que oponen estos conjuntos de textos, lejos de ser arbitrarias, forman dos conjuntos narrativos homogéneos que pueden ser calificados de «géneros» como lo ha sugerido Julien (2000). Las características del primer grupo, que reúne las versiones de Las Casas, Román, Gutiérrez y Betanzos, se emparentan con las descripciones de los cantares épicos que fueron propiedad de cada familia noble. Como se ha resumido anteriormente, estos relatos alababan el mérito individual de los reyes-antepasados, su valentía en el combate, ingeniosidad militar, habilidad política y capacidad para movilizar aliados poderosos fuera del linaje real principal. Su carácter y vigor juvenil contrastan con la escasa virtud del hermano mayor. Estos mismos relatos unen a los reyes con esposas principales extranjeras al linaje real. Ellas disfrutaban de un papel político y diplomático importante que, como su marido, les daba el poder de actuar en la renovación histórica de las instituciones del imperio (cuadro 1). 
Cuadro 1 - Las oposiciones dualistas en los relatos épicos

\begin{tabular}{|l|l|}
\hline \multicolumn{1}{|c|}{ HANAN } & \multicolumn{1}{c|}{ HURIN } \\
\hline - Trastorno del orden establecido. & - Perpetuidad de las normas prescritas. \\
- Elección del pretendiente más apto. & - Primogenitura. \\
- Exogamia. & - Endogamia. \\
- Condensación temporal, & - Extensión temporal, sucesión linear de \\
contemporaneidad de las parentelas. & las parentelas. \\
- Hijo menor, originario de una rama & - Hijo mayor, procedente del Qhapaq \\
cadete. & Ayllu. \\
- Aliados fuera del linaje dirigente. & - Aliados limitados al linaje dirigente. \\
- Soberano virtuoso, dinámico. & - Soberano laxo, apático. \\
- Expansión territorial. & - Dominio restringido. \\
\hline
\end{tabular}

Así, la relación fraternal asimétrica entre hermano mayor y cadete se encuentra en el núcleo de la estructura dualista inca. No solamente la organización de las parentelas dentro del grupo de descendencia real obedece a esta regla básica de estratificación social, también los relatos discordantes de la creación de las mitades expresan las tensiones inherentes a este sistema de sucesión dinástico basado en la primogenitura. La composición de Hanan y Hurin, entonces, no era inmutable ya que ofrecía una representación de la situación política en un momento preciso de la historia. Si esta organización se estabilizó en una estructura fija simultáneamente con la instauración de la administración colonial, originalmente fue una configuración social propensa al cambio por su apertura a la elección del más apto entre los candidatos originarios de diversas ramas cadetes del ayllu real.

\section{CONCLUSIÓN}

Los soberanos de Hanan Cuzco ofrecieron modelos de conducta ideal ya que fueron ellos quienes se levantaron contra la pasividad de sus abuelos y se rehusaron a que el reino cayera en manos incompetentes. Fue a ellos también a quienes las fuentes coloniales, sin distinción de autores, atribuyeron la expansión del imperio inca, de modo que en los relatos de tipo épico la perpetuidad de la dinastía está basada en el derrocamiento del orden establecido. Estas narraciones contrastan con el género genealógico donde toda rivalidad entre facciones está ausente y donde la continuidad de la dinastía se funda sobre el estricto respecto de la regla de sucesión. Los relatos genealógicos transmiten a la vez la imagen de una sociedad con gran estabilidad interna, unida contra enemigos exteriores, y la de un sistema de organización social de gran durabilidad. En las fuentes coloniales, estos dos géneros de discurso están estrechamente entreverados y es raro que los cronistas sostengan una única trama narrativa en el curso de cada obra. Sarmiento, por ejemplo, recolectó materiales tan diversos ante la nobleza indígena, inca como 
provincial, que condensa las tradiciones históricas de diferentes tipos narrativos. Su evocación casi linear de la dinastía, de las rebeliones de etnias rivales contra los incas y de las guerras de conquista que van en aumento, está compuesta de elementos procedentes de versiones alternativas de la historia que él atribuye a «otros indios». Betanzos, al contrario, se inspiró ampliamente del discurso épico de la vida del Inca Pachacuti, de tal modo que su relación sigue las mismas convenciones narrativas en su transcurso. Solo incorpora algunos datos sociológicos para aclarar su informe. Estos cronistas, como los demás, no formularon ni la regla de primogenitura ni la genealogía linear de los reyes incas a partir de su propia imaginación. Más bien, recurrieron a las tradiciones nativas que mejor correspondían a su concepción del orden social y a su ambición personal de crear una obra que reflejase las preocupaciones de su tiempo. Sin duda son numerosas las relaciones intertextuales entre las fuentes históricas que derivan de la intención de los cronistas de ampliar a proyectos políticos e intelectuales ya iniciados en escritos posteriores. Mucho se ha discutido acerca de estos vínculos literarios y, por supuesto, queda mucho más por investigar sobre el tema. Sin embargo, este artículo desea llamar la atención sobre el tema, a menudo olvidado, de las circunstancias político-sociales en que las narraciones incas fueron elaboradas. Ambos contextos de producción (pre y Posconquista) componen de igual modo la dinámica historiográfica andina. Por eso, el análisis comparativo de los registros narrativos y un entendimiento más preciso de los principios de filiación incas son necesarios para aclarar la discordancia factual entre las crónicas.

Además, este tipo de discordancias en los registros históricos no es propio de los incas. En 1972, Valerio Valeri reexaminó las representaciones contradictorias que oponen las narraciones históricas con los cantares genealógicos recogidos en Hawái a partir del siglo XVIII14. Demostró que estas formas de elaboraciones históricas coexistieron a través del tiempo, pero circularon en contextos discursivos diferentes. Cada una comunicaba un discurso de legitimación de la institución real utilizando distintos argumentos persuasivos. Al igual que en esta sociedad, la riqueza narrativa de los relatos dinásticos incas demuestra que, antes de la invasión española, los incas también concibieron la superioridad de un sistema de representación del pasado que exalta el derrocamiento del orden prescrito, la innovación y temeridad personal. Porque es la supremacía del ideal disidente la que los incas afirman cuando otorgan ascendencia social y cargos de prestigio a los Hanan Cuzcos, los mismos que descendían de los soberanos insubordinados a las leyes estáticas de reproducción del modelo social. A través de estas tradiciones, proclaman a su auditorio que el imperio nunca habría alcanzado tal grandeza si sus dirigentes hubieran reproducido ciegamente las reglas recibidas. Con esta

14 Los corpus inca y hawaiano plantean problemas metodológicos similares. Valeri (1972: 37) observa que «la gran preocupación de los que estudiaron las tradiciones y particularmente las genealogías hawaianas fue encontrar a toda costa una 'tradición única' y una 'genealogía única'». Según él, esta tendencia dio lugar a un «trabajo injustificable de manipulaciones y de recortes de genealogías» (Valeri, 1972: 37). Aunque dejo al cuidado de los especialistas juzgar la validez de estas afirmaciones, la historiografía hawaiana contemporánea pone a disposición claves de lectura muy pertinentes. 
reflexión, la historia del imperio registrada en fragmentos en las crónicas, se revela en parte como autónoma del predominio de los actores coloniales. Dicha historia expresa sus propias contradicciones internas que fueron los provechos de la emulación concienzudamente sustentada por una sociedad conquistadora. En este sentido, su formulación dialéctica que contraponía las reglas tradicionalistas y estructurales a los agentes reformadores y adaptativos instauraba una rivalidad productiva al nivel más alto del ejercicio del poder. Este tipo de tensión se encuentra también en otras manifestaciones dualistas andinas hasta el día de hoy. Así, la etnografía actual documenta varios casos de competiciones entre mitades que tienen el objetivo de estimular la máxima eficacia y excelencia en contextos rituales o durante los trabajos comunitarios (Palomino-Flores, 1971; Spalding, 1984: 56-60; Gelles, 2000: 105 y ss.). De esa manera, la tradición histórica inca no fue únicamente un repositorio de hechos memorables que proponían a la posteridad unos modelos fijos de éxito. Más bien, sus contenidos fluctuaban en función de los cambios políticos para legitimar la autoridad de los linajes en el poder. Era «un saber en el presente» (un savoir au présent)15 lejos de un registro mitológico que habría transmitido un sistema social con principios inmutables. Lejos también de un registro objetivo de hechos a partir del cual se debe extraer el informe auténtico de lo que realmente pasó. Sobre esta última cuestión, la investigación arqueológica emancipada del modelo dinástico propuesto por los cronistas nos ofrecerá datos más adecuados. En cuanto a los relatos de la creación de las mitades cuzqueñas, informan sobre los principios que ordenaron la jerarquía de prestigio, pero también recuerdan el acomodo que los actores históricos impusieron sobre este sistema.

\section{Agradecimientos}

Deseo expresar mi gratitud a las organizadoras del seminario y a los participantes por los valiosos comentarios que contribuyeron a mejorar el argumento. También agradezco a Blanca Tovías por sus valiosas sugerencias a la primera redacción, y a los dos evaluadores por su lectura atenta del manuscrito final y sus incisivos comentarios.

\section{Referencias citadas}

ACOSTA, J. de, 1962 [1590] - Historia natural y moral de las Indias, 444 pp.; México: Fondo de Cultura Económica.

ÁLVAREZ-CALDERÓN, A., 2007 - La crónica de Fray Martín de Murúa: mentiras y legados de un mercedario vasco en los Andes. Revista Andina, 45: 159-186.

ARELLANO HOFFMANN, C., 1998 - Hanan/Urin: reflexiones acerca de un viejo concepto dual Inka y su aplicación en el Chinchaysuyu. In: 50 años de Estudios Americanistas en la Universidad de Bonn: nuevas contribuciones a la arqueología, etnohistoria,

\footnotetext{
15 Se extrae aquí una fórmula de Marcel Détienne (1981: 79) sobre las tradiciones memoriales.
} 
etnolingüística y etnografía de las Américas, B.A.S. 30 (S. Dedenbach-Salazar Sáenz, C. Arellano Hoffman, E. Köning \& H. Prümers, eds.): 473-493; Bonn Verlag: Anton Saurwein.

BETANZOS, J. de, 1987 [1551] - Suma y narración de los Incas, 317 pp.; Madrid: Editorial Atlas.

CABELLO BALBOA, M., 1951 [1586] - Miscelánea Antártica, una historia del Perú antiguo, 561 pp.; Lima: Universidad Nacional Mayor de San Marcos, Instituto de Etnología.

CERRÓN-PALOMINO, R., 2002 - Hurin: un espejismo léxico opuesto a hanan. In: EI Hombre y los Andes: Homenaje a Franklin Pease G. Y., Vol. 1 (J. Flores Espinoza \& R. Varón Gabai, eds.): 219-235; Lima: Pontificia Universidad Católica del Perú.

CIEZA DE LEÓN, P., 1996 [1554] - Segunda parte de la crónica del Perú: El señorío de los Incas, 238 pp.; Lima: Pontificia Universidad Católica del Perú.

COBO, B., 1964 [1653] - Historia del Nuevo Mundo, Vol. 2, 92, 515 pp.; Madrid: Editorial Atlas.

COVEY, A. R., 2006 - Chronology, succession, and sovereignty: the politics of Inka historiography and its modern interpretation. Comparative Study of Society and History, 48 (1): 169-199.

CUMMINS, T., 2002 - Toasts with the Inca: Andean abstraction and colonial images on quero vessels, 377 pp.; Ann Arbor: University of Michigan Press.

CUNOW, H., 1929 - El sistema de parentesco peruano y las comunidades gentilicias de los incas, 78 pp.; París: Le Livre libre.

DÉTIENNE, M., 1981 - L'invention de la mythologie, 252 pp.; París: Gallimard.

Discurso sobre la descendencia y gobierno de los Incas ou Declaración de los quipocamayos a Vaca de Castro, 1920 [1543-1608] - In: Informaciones sobre el antiguo Perú. Segunda ser. 3 (H. H. Urteaga, ed.): 3-53; Lima: Sanmartí y Ca.

DUVIOLS, P., 1971 - La lutte contre les religions autochtones dans le Pérou colonial : l'extirpation de l'idolâtrie entre 1532 et 1600, 428 pp.; Lima: Institut Français d'Études Andines.

DUVIOLS, P., 1973 - Huari y Llacuaz. Agricultores y pastores. Un dualismo prehispánico de oposición y complementariedad. Revista del Museo Nacional, 39: 153-191.

DUVIOLS, P., 1979a - Datation, paternité et idéologie de la «Declaración de los quipucamayos a Vaca de Castro» (Discurso de la descendencia y gobierno de los Ingas). In: Les cultures ibériques en devenir : essais publiés en hommage à la mémoire de Marcel Bataillon (1895-1977): 583-591; París: La Fondation Singer-Polignac.

DUVIOLS, P., 1979b - La dinastía de los Incas: imonarquía o diarquía? Argumentos heurísticos a favor de una tesis estructuralista. Journal de la Société des Américanistes, LXVI: 67-83.

FERNÁNDEZ, D., 1963 [1571] - Historia del Perú, 409 pp.; Madrid: Editorial Atlas. Biblioteca de Autores Españoles 165.

FIRTH, R., 1957 - Note on descent groups in Polynesia. Man, 57: 4-8.

GARCILASO DE LA VEGA, I., 1985 [1609] - Comentarios Reales de los Incas, 2 vols.; Caracas: Biblioteca Ayacucho.

GELLES, P., 2000 - Water and power in highland Peru. The cultural politics of irrigation and development, 233 pp.; New Brunswick: Rutgers.

GOLDMAN, I., 1970 - Ancient Polynesian society, 625 pp.; Chicago: University of Chicago Press.

GONZÁLEZ HOLGUÍN, D., 1842 [1607] - Gramática y arte nueva de la lengua general de todo el Perú, 320 pp.; Genève: Pagano. 
GONZÁlEZ HOLGuíN, D., 1952 [1608] - Vocabulario de la lengua general de todo el Perú, 707 pp.; Lima: Imprenta Santa María.

GOSE, P., 1996 - The past is a lower moiety. History and Anthropology, 9 (4): 383-414.

GUTIÉRREZ DE SANTA CLARA, P., 1963-1964 [C. 1590] - Quinquenarios o Historia de las guerras civiles del Perú, 422 pp.; Madrid: Editorial Atlas. Biblioteca de Autores Españoles 166.

HAGE, P. \& HARARY, F., 1996 - Island networks. Communication, kinship and classification structures in Oceania, 296 pp.; Cambridge: Cambridge University Press.

HERNÁNDEZ ASTETE, F., 2008 - Las panacas y el poder en el Tahuantinsuyo. Bulletin de I'Institut Français d'Études Andines, 37 (1): 29-45.

ISBELL, B. J., 1978 - To defend ourselves. Ecology and ritual in an Andean village, 289 pp.; Austin: University of Texas Press.

ITIER, C., 2011 - Las panacas no existieron. In: Aru, Simi, Taqu, Lengua: Estudios en homenaje a Rodolfo Cerrón-Palomino (W. F. H. Adelaar, P. Valenzuela Bismarck \& R. Zariquiey Biondi, eds.): 181-193; Lima: Pontificia Universidad Católica del Perú.

JENKINS, D., 2001 - The Inka conical clan. Journal of Anthropological Research, 57 (2): 167-195.

JULIEN, C., 1998 - La organización parroquial del Cusco y la ciudad incaica. Tawantinsuyu, 5: 82-96.

JULIEN, C., 2000 - Reading Inca history, 338 pp; lowa City: University of lowa Press.

KIRCHHOFF, P., 1949 - The social and political organization of the Andean peoples. In: Handbook of South American Indians, Vol. 5 (J. H. Steward, ed.): 293-311; Washington: Government Printing Office.

LAS CASAS, B. de, 1909 [1562-1564] - Apologética historia de las Indias, 704 pp.; Madrid: Editorial Atlas. Biblioteca de Autores Españoles, 105-106.

MACCORMACK, S., 1991 - Religion in the Andes, vision and imagination in early colonial Peru, 488 pp., Princeton: Princeton University Press.

MAZZOTTI, J. A., 2008 - Incan Insights. El Inca Garcilaso's Hints to Andean Readers, 352 pp.; Frankfurt: Iberoamericana Editorial Vervuert.

MOLINA, C. de, 1989 [1575] - Relación de las fábulas y ritos de los Incas. In: Fábulas y mitos de los Incas (H. Urbano \& P. Duviols, eds.): 48-134; Madrid: Historia 16.

MURÚA, M., 2001 [1590-1602] - Historia general del Perú, 571 pp.; Madrid: Dastin Historia.

PALOMINO FLORES, S., 1971 - La dualidad en la organización sociocultural de algunos pueblos del área andina. Revista del Museo Nacional, 37: 231-260.

PÄRSSINEN, M., 1992 - Tawantinsuyu: the Inca state and its political organization, 462 pp.; Helsinki: Societas Historica Finlandiae. Studia Historica 43.

PEASE, F. G. Y., 1991 [1972] - Los últimos incas del CusCo, 184 pp.; Madrid: Alianza Editorial.

PORRAS BARRENECHEA, R., 1999 [1947] - El legado quechua, 421 pp.; Lima: Universidad Nacional Mayor de San Marcos.

RAMÍREZ, S. E., 2006 - Historia y memoria: la construcción de las tradiciones dinásticas andinas. Revista de Indias, 66 (236): 13-56.

ROMÁN Y ZAMORA, J., 1897 [1575] - Repúblicas de Indias, idolatrias y gobierno antes de la conquista. Colección de Libros Españoles Raros o Curiosos que tratan de América XIV-XV; Madrid: Victoriano Suarez Editor. 
ROSTWOROWSKI, M., 1960 - Succesion, cooption to kingship, and royal incest among the Inca. Southwestern Journal of Anthropology, 16 (4): 417-427.

ROSTWOROWSKI, M., 1977 - La estratificación social y el Hatun Curaca en el mundo Andino. Histórica, I (2): 249-285.

ROSTWOROWSKI M., 1983 - Estructuras andinas del poder. Ideología religiosa y política, 202 pp.; Lima: Instituto de Estudios Peruanos.

ROSTWOROWSKI, M., 1988 - Historia del Tahuantinsuyu, 332 pp.; Lima: Instituto de Estudios Peruanos, Ministerio de la Presidencia, Consejo Nacional de Ciencia y Tecnología.

ROWE, J. H., 1946 - Inca culture at the time of the spanish conquest. In: Handbook of South American Indians, Vol. 2 (J. H. Steward, ed.): 183-330; Washington D.C.: Smithsonian Institution, Bureau of American ethnology.

ROWE, J. H., 1985 - Probanza de los Incas nietos de conquistadores. Histórica, IX (2): 193-254.

SAHLINS, M. D., 1958 - Social stratification in Polynesia, 306 pp.; Seattle: University of Washington Press.

SALOMON, F., 1999 - Testimonies: the making and reading of native South American historical sources. In: The Cambridge History of the Native Peoples of the Americas, South America, Part 1, Vol. 3 (F. Salomon \& S. B. Schwartz, eds.): 19-95; Cambridge: Cambridge University Press.

SARMIENTO DE GAMBOA, P., 1988 [1572] - Historia de los Incas, 191 pp.; Madrid: Miraguano-Polifemo Ediciones.

SELER, E. G., 1915 [1894] - Über die sociale Stellung des Khapak Inca. In: Compte rendu du Congrès International des Américanistes, dixième session: 9-19; Stockholm: Ivar Hæggström.

SPALDING, K., 1974 - De indio a campesino: Cambios en la estructura social del Perú colonial, 258 pp.; Lima: Instituto de Estudios Peruanos.

SPALDING, K., 1984 - Huarochirí, an Andean society under Inca and Spanish rule, 364 pp.; Stanford: Stanford University Press.

VALCÁRCEL, L. E., 1925 - Del ayllu al imperio: la evolución político-social en el antiguo Perú y otros estudios, 201 pp.; Lima: Editorial Garcilaso.

VALERI, V., 1972 - Le fonctionnement du système des rangs à Hawaii. L'Homme, 12 (1): 29-66.

VILLARÍAS ROBLES, J. J., 1998 - El sistema económico del imperio inca. Historia crítica de una controversia, 362 pp.; Madrid: CSIC, Centro de Estudios Históricos.

ZUIDEMA, R. T., 1962 - The ceque system of CuzCo, the social organization of the capital of the Inca, 305 pp.; Leiden: E. J. Brill.

ZUIDEMA, R. T., 1982 - Myth and history in ancient Peru. In: The logic of culture, advances in structural theory and method (I. Rossi, ed.): 150-175; South Hadley: J. F. Begin Publishers.

ZUIDEMA, R. T., 1986 - La civilisation inca au Cuzco, 111 pp.; París: Presses Universitaires de France. Collège de France: Essais et Conférences. 